\title{
Faktor Internal dan Eksternal Perbankan Syariah yang Mempengaruhi Tindakan Perataan Laba
}

\section{Internal and external factors of Islamic banking that affect income smoothing actions}

\section{Ros Melinda}

Program Studi D4 Keuangan Syariah, Politeknik Negeri Bandung

E-mail: rosmelinda2812@gmail.com

\section{Setiawan}

Jurusan Akuntansi, Politeknik Negeri Bandung

E-mail: setiawan@polban.ac.id

\begin{abstract}
The purpose of this study is to find out and analyze internal factors and external factors of Islamic banking which can affect the practice of income smoothing. This research was conducted at sharia commercial banks in Indonesia for the period 2013 to 2017. The population in this study amounted to 11 Islamic Commercial Banks. After sampling technique using a purposive sampling method, 10 Islamic banks were obtained which will be used as samples in the study. Whereas to see the influence of the independent variables on the dependent variable used panel data regression analysis method. Based on the results of the study it is known that simultaneously, profitability (earnings before tax and provisions), the amount of financing, Non-Performing Financing, Good Corporate Governance (the existence of the Sharia Supervisory Board), Gross Domestic Product, and the inflation rate affect income smoothing. While partially, only the variable profitability (earnings before tax and provisions), the amount of financing, and Non-Performing Financing that influence the practice of income smoothing in Islamic banking in Indonesia.
\end{abstract}

Keywords: Islamic Banking, Sharia Accounting, Profit Management, Income Smoothing

\section{Pendahuluan}

Informasi laba adalah salah satu komponen laporan keuangan yang memiliki tujuan untuk membantu mengestimasikan kemampuan laba yang reprsentatif dalam jangka panjang, menilai kinerja dari manajemen, dan menaksir risiko investasi (Irawati \& Maya, 2007). Tidak dapat dipungkiri bahwa laba menjadi informasi yang penting baik para calon investor untuk melakukan pengambilan keputusan mengenai investasi yang akan dilakukannya dan dari laba tersebut dapat mengukur kinerja manajemen (Prakarsa \& Setiawan, 2018). Kecenderungan para investor dan juga penilaian kinerja manajemen yang terpusat pada informasi laba maka dapat menimbulkan disfunctional behavior, karena manajemen memiliki kecenderungan untuk melakukan tindakan yang menjadikan laba lebih stabil (Utari, Gustini, \& Tripermata, 2017).

Salah satu tindakan manajemen agar kinerjanya dapat dinilai baik adalah dengan melakukan earning management. Manajemen laba (earning management) adalah pemiliihan kebijakan akuntansi oleh manajemen yang berguna untuk mencapai beberapa tujuan tertentu (Utari, Gustini, \& Tripermata, 2017). Salah satu bentuk dari manajemen laba adalah perataan laba. Perataan laba merupakan suatu cara yang digunakan manajemen untuk menguranggi variabilitas arus laba laporan relatif pada arus laba yang diinginkan pada periode-periode yang berurutan (Kustono, 2010). Cara dari perataan laba ini tidak diperbolehkan dalam ruang lingkup prinsip akuntansi secara umum. Karena prinsip 
akuntansi mensyaratkan bahwa laba baru dapat diakui apabila ada kepastian laba tersebut dapat terealisasi dan diperoleh (Sulistiyanto, 2008). Selain itu, cara ini juga akan membuat laporan keuangan tidak mencerminkan kondisi perusahaan yang sebenarnya. Sehingga pengguna laporan keuanngan akan mendapatkan informasi yang menyesatkan dan melakukan kekeliruan dalam menilai kinerja perusahaan tesebut (Prakarsa \& Setiawan, 2018).

Secara empiris, Zoubi dan Al-Khazali (2007) menemukan bukti praktik perataan laba pada sampel yang terdiri dari 65 bank konvensional dan bank syariah yang beroperasi di Gulf Cooperation Council (GCC), mereka berpendapat bahwa para manajer menggunakan Loan Loss Provisions (LLP) untuk mengheluskan pendapatan selama periode 2002-2003. Sejalan dengan pemikiran dari Syahfandi (2012) menemukan adanya praktik manajemen laba dengan perataan laba pada Bank syariah di Indonesia, dari 9 sampel yang digunakan ditemukan 6 bank syariah yang melakukan perataan laba dengan menggunakan Penyisihan Penghapusan Aktiva Produktif (PPAP). Akan tetapi, penelitian yang dilakukan oleh Boulila, et al. (2010) menyatakan bahwa meraka tidak menemukan adanya praktik manajemen laba dengan perataan laba yang menggunakan mekanisme Loan Loss Provisions.

Perataan laba yang diproksikan dengan PPAP didasari oleh fakta bahwa perubahan dari PPAP tidak mempengaruhi arus kas tersebut, serta PPAP merupakan pretax item, jadi apabila nilai PPAP mengalami perubahan, maka akan berpengaruh pada nilai laba bersih yang dihasilkan atau jumlah pajak yang dibayarkan (Syahfandi, 2012). Tujuan dibentuknya PPAP adalah alat untuk penerapan prinsip kehati-hatian (prudential banking). PPAP menunjukkan sejumlah kerugian yang diperkirakan atas saldo pinjaman atau invastasi yang belum diselesaikan dan sebagai salah satu akun kontra aset. Dalam laporan keuangan PPAP dimasukkan ke dalam laporan laba rugi sebagai akun pengurang yang merupakan salah satu beban yang ditanggung bank pada periode pelaporan keuangan. Artinya PPAP memiliki nilai yang signifikan dalam laporan keuangan dan merupakan area yang memiliki potensi untuk dimanipulasi oleh para manajer (Tobing \& Anggrowati, 2009).

Tabel 1. Nilai Hasil Indeks Eckel

\begin{tabular}{|c|l|c|l|}
\hline No & \multicolumn{1}{|c|}{ Nama Bank } & Indeks Eckel & \multicolumn{1}{c|}{ Keterangan } \\
\hline 1 & Bank Syariah Bukopin & 2,389 & Bukan Pelaku Perataan Laba \\
\hline 2 & Bank BNI Syariah & 0,339 & Pelaku Perataan Laba \\
\hline 3 & Bank BRI Syariah & 0,160 & Pelaku Perataan Laba \\
\hline 4 & Bank BCA Syariah & 0,285 & Pelaku Perataan Laba \\
\hline 5 & Bank Panin Syariah & 19,801 & Bukan Pelaku Perataan Laba \\
\hline 6 & Bank Muamalat & 0,404 & Pelaku Perataan Laba \\
\hline 7 & Bank Mega Syariah & 0,029 & Pelaku Perataan Laba \\
\hline 8 & Bank Victoria Syariah & 1,943 & Bukan Pelaku Perataan Laba \\
\hline 9 & Bank Maybank Syariah & 10,016 & Bukan Pelaku Perataan Laba \\
\hline 10 & Bank Syariah Mandiri & 0,715 & Pelaku Perataan Laba \\
\hline Jumlah Bank pelaku perataan laba & $6(60 \%)$ \\
\hline Jumlah Bank bukan pelaku perataan laba & $4(40 \%)$ \\
\hline Jumlah & & $10(100 \%)$ \\
\hline
\end{tabular}

Sumber : data sekunder yang diolah, 2018

Adanya praktik perataan laba dapat dilakukan dengan menggunakan perhitungan Indeks Eckel, yaitu dengan perbandingan koefisien variasi dari perubahan laba bersih (net income) dengan koefisien variasi dari perubahan total pendapatan bersih. Untuk menguatkan fenomena yang ada penulis melakukan perhitungan indeks eckel dengan sampel 10 bank umum syariah di Indonesia dengan melakukan purposive sampling. Angka indeks yang kurang dari 1 diklasifikasikan sebagai perata laba 
(income Smoother), sedangkan lebih besar dari 1 diklasifikasikan bukan perata laba (Kustono, 2010), hasil dari perhitungan indeks Eckel nampak pada tabel 1 di atas.

Adanya bukti praktik perataan laba pada perbankan syariah maka dapat diduga adanya faktor internal yang mempengaruhi praktik perataan laba dan selain dari faktor internal dari bank syariah itu sendiri dapat diduga adanya faktor eksternal yang turut andil mempengaruhi manajer untuk melakukan praktik perataan laba. Berdasarkan penelitian yang sebelumnya maka perumusan masalah dalam penelitian ini adalah untuk menganalisis faktor internal dan faktor eksternal yang mempengaruhi praktik perataan laba pada bank umum syariah. Faktor internal yang digunakan dalam penelitian ini adalah profitabiliitas (earning before taxes and provisions), risiko pembiayaan (nonperforming financing), good corporate governance (keberadaan DPS), jumlah pembiayaan (total financing), dan Sedangkan faktor eksternal yang diduga dapat mempengaruhi praktik perataan laba adalah Gross Domestic Product (GDP) dan inflasi.

\section{Kajian Pustaka}

\subsection{Perataan Laba}

Perataan laba (income smoothing) merupakan salah satu pola tindakan manajemen laba yang kerap kali dilakukan oleh manajer dengan tunjuan untuk melaporkan laporan keuangan dengan keuntungan yang relatif stabil. Perataan laba merupakan praktik yang dilakukan dengan cara melakukan pengurangan dalam variabilitas laba dengan sejumlah tetentu pada satu periode atau periode tertentu sampai mengarah pada tingkat laba yang diharapkan pada laporan keuangan yang dipublikasikan (Assih \& Gudono, 2000).

Konsep income smoothing dalam perbankan dikenal dengan istilah dynamic provisioning yang merupakan penyangga yang digunakan bank dalam mengatasi masa-masa sulitnya dengan menciptakan penyangga pada masa-masa baiknya. Dynamic provisioning dapat dijadikan instrumen kebijakan dalam penerapan prinsip kehati-hatian (prudential banking) yang sangat tepat bagi negaranegara berkembang (Syahfandi, 2012). Bahkan jika terdapat ketidakstabilan ekonomi yang tinggi dan besarnya peran perbankan dalam intermediasi keuangan. Syarat adanya dynamicc provisioning harus dikelola secara transparansi, untuk menghindari manajemen laba tersebut. Keberadaan income smoothing meningkatkan daya tahan perbankan, baik individu maupun secara keseluruhan, meskipun tidak ada jaminan bahwa bank-bank tersebut dapat mengatasi permasalahan kreditnya (Pe'rez, Salas, \& Saurina, 2006).

Menurut pandangan Islam, perataan laba bertentangan dengan kaidah fiqh muamalah karena mengandung unsur penipuan (tadlis) dan ketidakjelasan (gharar) ada pihak yang menyembunyikan informasi terhadap pihak yang lain (unknown to one party) dengan maksud untuk menipu pihak lain atas ketidaktahuannya tentang informasi tersebut (Arisandy, 2015). Perataan laba yang dilakukan dengan cara meratakan laba yang dilaporkan sehingga dapat mengurangi fluktuasi laba yang terlalu besar karena pada umumnya investor lebih menyukai laba yang relatif stabil. Hal tersebut jelas tidak diperbolehkan dalam syariat Islam, karena mengambil keuntungan dengan melakukan tindakan menipu atau menyamarkan perdagangan dengan menyembunyikan cacatnya barang dagangan, atau menampakkannya (mengemasnya) dalam bentuk yang menipu, yang tidak sesuai dengan hakikatnya, dengan tujuan mengecoh pembeli, tidak diperbolehkan (Arisandy, 2015). Hal ini menyebabkan laporan keuangan tidak mencerminkan kinerja perusahan yang sebenarnya. Penjelasan Al-Qur'an dan Hadits mengenai larangan mengambil keuntungan dengan jalan menipu, diantaranya Surat An-Nisa ayat 29, yang artinya:

"Hai orang-orang yang beriman, janganlah kamu saling memakan harta sesamamu dengan jalan yang batil, kecuali dengan jalan perniagaan yang berlaku dengan suka sama-suka di 
antara kamu. Dan janganlah kamu membunuh dirimu; sesungguhnya Allah adalah Maha Penyayang kepadamu."

Dalam ayat tersebut diterangkan bahwa transaksi bisnis tidak boleh dilakukan dengan jalan yang bathil dan perlu adanya keridhoan dalam melakukan transaksi. Sedangkan dalam manajemen laba, manajer keuangan melakukan pelaporan keuangan yang telah di modifikasi agar memperoleh keuntungan. Misalnya dengan menurunkan jumlah laba yang akan dilaporkan padahal perusahaan memperoleh tingkat profitabilitas yang tinggi dengan maksud untuk memperoleh perhatian secara politis. Hal tersebut tidaklah diperbolehkan karena tidak mengandung unsur kejujuran didalamnya. Bisnis yang dilakukan dalam syariat Islam tidak hanya berorientasi pada keuntungan saja namun juga berorientasi pada kejelasan, kejujuran, keridhoan antar pelaku bisnis dan keberkahan dalam transaksi bisnis.

\subsection{Kerangka Pemikiran dan Hipotesis}

Hal yang mendasari dari penelitian ini adalah karena adanya kecenderungan para investor dan juga penilaian kinerja manajemen yang terpusat pada informasi laba, maka manajemen memiliki kecenderungan untuk melakukan tindakan yang menjadikan laba lebih stabil. Cara untuk menjadikan laba lebih stabil adalah dengan melakukan perataan laba (income smoothing). Dari penelitian yang telah dilakukan oleh Zoubi dan al-Khazali (2007) dan Syahfandi (2012) telah menemukan bahwa adanya praktik perataan laba pada bank syariah dengan menggunakan PPAP. Berdasarkan telaah pustaka dan penelitiaan terdahulu yang telah diuraikan sebelumnya, maka penelitian ini menjelaskan kemungkinan adanya praktik perataan laba pada bank syariah yang diproksikan dengan menggunakan PPAP.

Tahap selanjutnya adalah menguji faktor-faktor yang mempengaruhi praktik perataan laba. Tingkat kepatuhan bank syariah yang tercermin dalam pelaksanaan Corporate Governance, jumlah kredit yang diproksikan dengan TF (total pembiayaan), risiko kredit bank yang diproksikan dengan NPF (Non Performing Financing), profitabilitas yang diproksikan dengan EBTP (Earning before Taxes and Provisions), GDP (Gross Domestic Product), dan tingkat inflasi diduga mempengaruhi adanya praktik manajemen laba dengan perataan laba menggunakan cadangan PPAP.

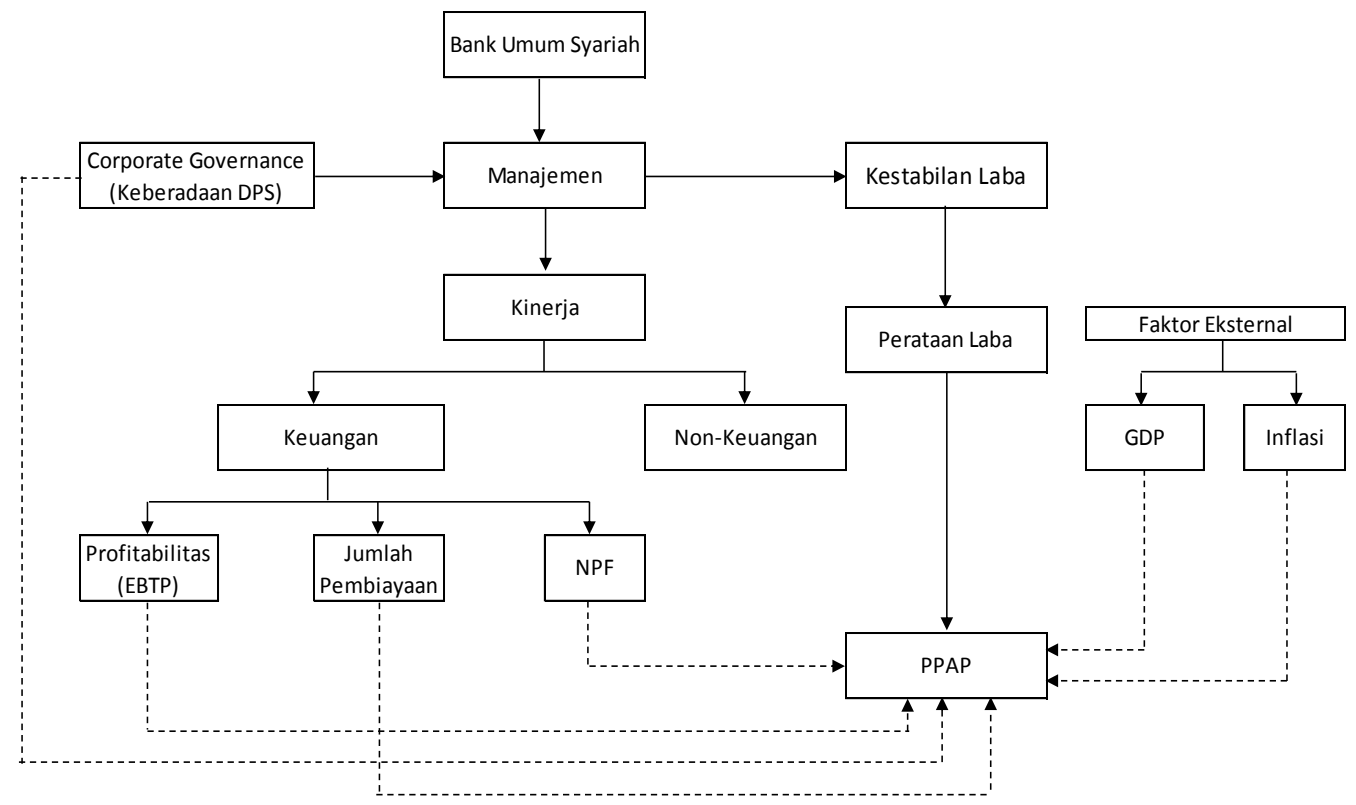

Gambar 1. Kerangka Pemikiran

Sumber: dari berbagai sumber (data diolab kembali) 
Dari kerangka pemikiran tersebut, maka kerangka hipotesis dalam penelitian ini adalah sebagai berikut:

$\mathrm{H}_{1}$ : Profitabilitas (Earnings Before Taxes and Provisions) berpengaruh terhadap perataan laba.

$\mathrm{H}_{2}$ : Risiko pembiayaan (Non performing financing) berpengaruh terhadap perataan laba.

$\mathrm{H}_{3}$ : Good Corporate Governance (keberadaan Dewan Pengawas Syariah) berpengaruh terhadap perataan laba.

$\mathrm{H}_{4}$ : Jumlah pembiayaan (Total financing) berpengaruh terhadap perataan laba.

$\mathrm{H}_{5}$ : GDP (Gross Domestic Product) berpengaruh terhadap perataan laba.

$\mathrm{H}_{6}$ : Inflasi berpengaruh terhadap perataan laba.

\section{Metode Penelitian (Font: Garamound, size 13)}

Pengambilan sampel dalam penelitian ini dilakukan dengan cara purposive sampling agar memperoleh sampel sesuai dengan kriteria yang telah ditentukan. Berikut ini adalah kriteria yang digunakan untuk memilih sampel: i) Bank umum syariah skala nasional yang mempublikasikan laporan keuangan tahunan (annual report) untuk periode 2013 sampai dengan periode 2017 yang dinyatakan dalam rupiah (Rp); ii) Data laporan keuangan tersedia lengkap secara keseluruhan dan di dalamnya terdapat data yang dibutuhkan dalam penelitian, yaitu good corporate governance (Keberadaan Dewan Pengawas Syariah) Total pembiayaan, NPF (Non Performing Loan), EBTP (Earning Before Tax and Provision), PPAP (Penyisihan penghapusan aktiva produktif) Bank Syariah yang terpublikasi periode 2013 sampai dengan periode 2017.

Data yang digunakan dalam penelitian ini berasal dari laporan keuangan annual report bank umum syariah (BUS) dari tahun 2013 sampai dengan tahun 2017, yang dapat langsung diakses melalui situs Otoritas Jasa Keuangan (www.ojk.go.id) atau dari situs bank perusahaan sampel itu sendiri. Untuk memperoleh data faktor eksternal dari bank syariah dapat diakses melalui situs Badan Pusat Statistik (www.bps.go.id).

Teknik analisis yang digunakan dalam penelitian ini adalah regresi data panel Data diolah dengan menggunakan software microsoft office excel 2010 dan software statistic eviews 9. Data penel merupakan gabungan dari data cross section dan data time series, maka persamaan regresinya menggunakan alat eviews 9 sebagai berikut :

$$
P L=\alpha+\beta 1 E B T P+\beta 2 N P F+\beta 3 G C G+\beta 4 T F+\beta 5 G D P+\beta 6 \text { Inflasi }+\varepsilon
$$

Keterangan:

PL = Perataan Laba yang diproksikan dengan Penyisihan Penghapusan Aktiva Produktif umum dan khusus pada bank $i$ selama periode tahun berjalan

EBTP $=$ Total pendapatan sebelum dikurangi pajak dan zakat pada bank $i$ selama periode tahun berjalan

NPF $\quad=$ Rasio Non Performing Financing

GCG = Good Corporate Governance yang diproksikan dengan keberadaan Dewan Pengawas Syariah dalam Bank Syariah

TF = Total pembiayaan syariah yang diberikan pada bank $i$ selama periode tahun berjalan

GDP = Gross Domestic Product atas harga berlaku nominal selama periode tahun berjalan.

Inflasi $=$ Tingkat inflasi tahunan di Indonesia

\section{Hasil dan Pembahasan}

\subsection{Pemilihan Model Data}

Uji Lagrangge Multiplier digunakan untuk memilih apakah model Common Effect atau Random Effect yang lebih tepat digunakan dalam suatu model persamaan regresi data panel. Berikut ini adalah hasil dari uji Lagrange Multiplier. 
Tabel 2. Hasil Uji Lagrange Multiplier

\begin{tabular}{|c|c|c|c|}
\hline \multirow{2}{*}{$\begin{array}{l}\text { Lagrange Multiplier Tests } \\
\text { Null hypotheses: No effe } \\
\text { Alternative hypotheses: T } \\
\text { (all others) alternativ } \\
\end{array}$} & \multicolumn{3}{|c|}{ Test Hypothesis } \\
\hline & Cross-section & Time & Both \\
\hline Breusch-Pagan & $\begin{array}{l}10.98899 \\
(0.0009)\end{array}$ & $\begin{array}{l}2.124821 \\
(0.1449)\end{array}$ & $\begin{array}{l}13.11381 \\
(0.0003)\end{array}$ \\
\hline Honda & $\begin{array}{l}3.314964 \\
(0.0005)\end{array}$ & $\begin{array}{c}-1.457677 \\
-\end{array}$ & $\begin{array}{l}1.313301 \\
(0.0945)\end{array}$ \\
\hline King-Wu & $\begin{array}{l}3.314964 \\
(0.0005)\end{array}$ & $\begin{array}{c}-1.457677 \\
-\end{array}$ & $\begin{array}{l}0.625951 \\
(0.2657)\end{array}$ \\
\hline Standardized Honda & $\begin{array}{l}4.556344 \\
(0.0000)\end{array}$ & -0.751383 & -0.630591 \\
\hline Standardized King-Wu & $\begin{array}{l}4.556344 \\
(0.0000)\end{array}$ & $\begin{array}{c}-0.751383 \\
-\end{array}$ & $\begin{array}{c}-1.346609 \\
-\end{array}$ \\
\hline Gourierioux, et al.* & - & - & $\begin{array}{l}10.98899 \\
(<0.01)\end{array}$ \\
\hline $\begin{array}{r}\text { *Mixed chi-square asymp } \\
1 \% \\
5 \% \\
10 \%\end{array}$ & $\begin{array}{r}\text { totic critical value } \\
7.289 \\
4.321 \\
2.952\end{array}$ & & \\
\hline
\end{tabular}

Dari hasil pengujian dengan uji Lagrange Multiplier (LM) diatas dapat dilihat hasil bahwa nilai LM hitung adalah $0.0009<0.05$ artinya, nilai LM hitung $<$ chi-squared tabel maka yang dipilih adalah model common effect.

\subsection{Hasil Regresi Data Panel}

Berikut hasil regresi data panel model Common Effect.

\section{Tabel 3 Hasil Regresi Data Panel}

\begin{tabular}{|c|c|c|c|c|}
\hline \multicolumn{5}{|c|}{$\begin{array}{l}\text { Dependent Variable: PL } \\
\text { Method: Panel Least Squares } \\
\text { Date: } 07 / 04 / 19 \text { Time: } 16: 32 \\
\text { Sample: } 20132017 \\
\text { Periods included: } 5 \\
\text { Cross-sections included: } 10 \\
\text { Total panel (balanced) observations: } 50 \\
\end{array}$} \\
\hline Variable & Coefficient & Std. Error & t-Statistic & Prob. \\
\hline C & 56.13647 & 73.91364 & 0.759487 & 0.4517 \\
\hline EBTP & 0.607675 & 0.115170 & 5.276342 & 0.0000 \\
\hline NPF & -23.81060 & 7.900444 & -3.013831 & 0.0043 \\
\hline GCG & 0.314366 & 0.337653 & 0.931034 & 0.3570 \\
\hline TF & 0.389005 & 0.087831 & 4.429026 & 0.0001 \\
\hline GDP & -2.530756 & 3.208167 & -0.788848 & 0.4345 \\
\hline INFLASI & -5.921003 & 9.072737 & -0.652615 & 0.5175 \\
\hline R-squared & 0.774456 & \multicolumn{2}{|c|}{ Mean dependent var } & 11.82693 \\
\hline Adjusted R-squared & 0.742984 & \multicolumn{2}{|c|}{ S.D. dependent var } & 1.641388 \\
\hline S.E. of regression & 0.832129 & \multicolumn{2}{|c|}{ Akaike info criterion } & 2.599520 \\
\hline Sum squared resid & 29.77489 & \multicolumn{2}{|c|}{ Schwarz criterion } & 2.867203 \\
\hline Log likelihood & -57.98799 & \multirow{2}{*}{\multicolumn{2}{|c|}{$\begin{array}{l}\text { Hannan-Quinn criter. } \\
\text { Durbin-Watson stat }\end{array}$}} & 2.701455 \\
\hline F-statistic & 24.60833 & & & 1.165575 \\
\hline Prob(F-statistic) & 0.000000 & & & \\
\hline
\end{tabular}

Sumber: data sekunder yang diolah, 2019

Berdasarkan tabel di atas, maka diperoleh persamaan regresi data panel sebagai berikut: $P L=56,136+0,608 \mathrm{EBTP}-23,811 \mathrm{NPF}+0,314 G C G-2,531 G D P-5,921 \mathrm{INFL}$ ASI 


\subsection{Uji Asumsi Klasik}

Uji normalitas dilakukan dengan melihat nilai probabilitas pada grafik Jarque-Bera apabila nilai probabilitas Jarque-Bera $>0.05$ maka data terdistribusi normal.. Berdasarkan pengujian yang dilakukan dengan melihat grafik Jarque-Bera diperoleh output yang dapat dilihat pada Gambar 2 sebagai berikut:

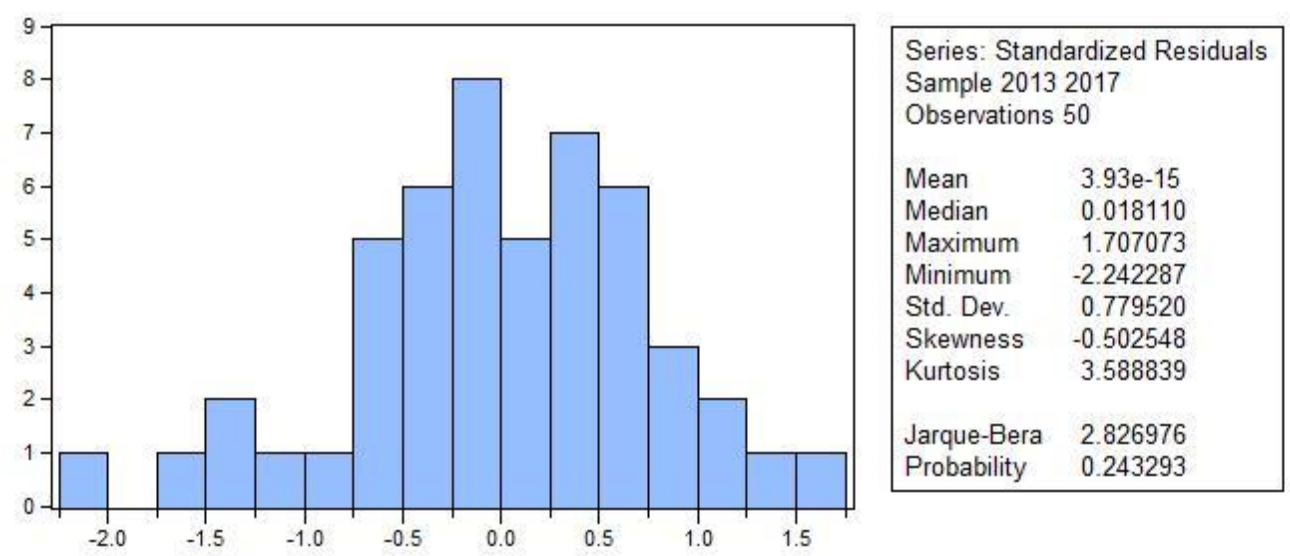

Gambar 2. Hasil Uji Normalitas

Berdasarkan hasil pengujian pada Gambar 2 menunjukan bahwa data telah terdistribusi secara normal karena nilai probabilitas Jarque-Bera sebesar 0.2432 yang berada di atas 0.05 . berikut:

Uji autokorelasi dalam penelitian ini dideteksi dengan menggunakan uji Durbin $W$ atson sebagai

Tabel 4. Hasil Uji Autokorelasi

\begin{tabular}{lrll}
\hline \hline R-squared & 0.774456 & Mean dependent var & 11.82693 \\
Adjusted R-squared & 0.742984 & S.D. dependent var & 1.641388 \\
S.E. of regression & 0.832129 & Akaike info criterion & 2.599520 \\
Sum squared resid & 29.77489 & Schwarz criterion & 2.867203 \\
Log likelihood & -57.98799 & Hannan-Quinn criter. & 2.701455 \\
F-statistic & 24.60833 & Durbin-Watson stat & 1.165575 \\
Prob(F-statistic) & 0.000000 & & \\
\hline \hline
\end{tabular}

Sumber: data sekunder yang diolah, 2019

Berdasarkan tabel 4 menunjukkan bahwa nilai dari Durbin-Watson untuk model common effect adalah sebesar 1.1656 berarti tidak terjadi autokorelasi karena nilai 1.1656 berada diantara -2 dan +2 .

Tabel 5 Hasil Uji Multikolinearitas

\begin{tabular}{crrrrrr}
\hline & EBTP & GCG & \multicolumn{1}{c}{ GDP } & \multicolumn{1}{c}{ INFLASI } & NPF & \multicolumn{1}{c}{ TF } \\
\hline \hline EBTP & 1.000000 & 0.613049 & 0.034879 & -0.027857 & 0.059159 & 0.539021 \\
GCG & 0.613049 & 1.000000 & $-1.76 \mathrm{E}-17$ & $-6.11 \mathrm{E}-18$ & 0.151324 & 0.477753 \\
GDP & 0.034879 & $-1.76 \mathrm{E}-17$ & 1.000000 & -0.845991 & 0.133190 & 0.217782 \\
INFLASI & -0.027857 & $-6.11 \mathrm{E}-18$ & -0.845991 & 1.000000 & -0.151658 & -0.260139 \\
NPF & 0.059159 & 0.151324 & 0.133190 & -0.151658 & 1.000000 & 0.152312 \\
TF & 0.539021 & 0.477753 & 0.217782 & -0.260139 & 0.152312 & 1.000000
\end{tabular}

Pada penelitian ini untuk melakukan uji multikolinearitas menggunakan Pearson Correlation. 
Kriteria Pearson Correlation untuk uji multikolinearitas adalah jika nilai koefisien korelasinya melebihi 0,9 maka terjadi multikolinearitas. Berikut hasil dari uji multikolineritas menggunakan Pearson Correlation: Berdasarkan hasil pengujian yang ditunjukkan pada tabel 5 nilai koefisien antar variabel lebih kecil dari 0.9. Maka dapat disimpulkan bahwa data tidak memiliki masalah multikolinearitas.

\subsection{Pembahasan}

Hasil uji statistik pada tabel 4 dapat menunjukkan bahwa EBTP berpenggaruh positif terhadap perataan laba karena memiliki nilai Prob. $<0.05$ yaitu sebesar 0.000 dan nilai pada koefisien regresi memiliki nilai yang positif. Diperolehnya hasil EBTP berpengaruh positif terhadap perataan laba maka dapat diartikan apabila bank memiliki tingkat keuntungan yang tinggi maka kecenderungan bank untuk melakukan perataan laba akan semakin tinggi juga. Karena disaat bank syariah mendapatkan keuntungan yang tinggi dan memprediksikan periode selanjutnya akan memperoleh kerugian maka bank syariah akan melakukan praktik perataan laba dengan mengurangi keuntungan pada periode saat ini dan digunakan ketika bank syariah mengalami kerugian. Hal ini dilakukan bank syariah adalah untuk memproleh laporan keuangan yang stabil.

Hasil uji statistik pada tabel 4 dapat dilihat bahwa NPF berpengaruh negatif terhadap perataan laba karena memiliki nilai Prob. $<0.05$ yaitu sebesar 0.004 dan memiliki nilai koefisien regresi yang negatif. Artinya apabila nilai NPF tinggi maka kecenderungan bank untuk melakukan perataan laba akan semakin rendah. Ketika nilai NPF tinggi maka risiko pembiayaan yang ditanggung oleh bank syariah juga tinggi. Nilai NPF yang tinggi menunjukkan adanya pembiayaan yang tinggi yang sedang beredar pada masyarakat. Bank dengan risiko pembiayaan yang tinggi akan memperbesar biaya, baik pencadangan dari aktiva produktif maupun biaya terkait lainnya, sehingga bank berpotensi akan mengalami kerugian. Saat bank syariah mengalami kerugian maka tidak dapat melakukan praktik perataan laba karena besaarny biaya yang disebabkan oleh risiko pembiayaan tersebut. Jadi, dapat disimpulkan apabila tingkat risiko pembiayaan meningkat maka kecenderungan bank untuk melakukan perataan laba akan semakin rendah.

Hasil analisis uji statistik pada tabel 4 menunjukkan hasil GCG tidak berpengaruh terhadap Perataan Laba dengan nilai Prob. $>0.05$ yaitu sebesar 0.357. Dengan kata lain dengan adanya keberadaan DPS dalam Bank Syariah tidak berpengaruh terhadap adanya praktik perataan laba. Berdasarkan hasil penelitian oleh Prabowo dan Jamal (2017) ditemukan adanya kelemahan dari Dewan Pengawas Syariah yaitu, masih banyak kasus pelnggaran mengenai prinsip-prinsip syariah yang dijalankan oleh perbankan syariah, terutama bagi bank yang telah melakukan konversi ke syariah atau baru saja membuka Unit Usaha Syariahnya. Hal ini berdampak pada peran Dewan Pengawas Syariah yag kurang optimal dalam melakukan pengawasan operasional Bank Syariah. Hal ini dapat mendukung dari hasil penelitian ini yang menunjukkan bahwa GCG yang diproksikan dengan keberadaan DPS tidak berpengaruh terhadap perataan laba.

Hasil uji statistik pada tabel 4 menunjukkan bahwa Jumlah Pembiayaan berpengaruh positif terhadap perataan laba karena memiliki nilai Prob. $<0.05$ yaitu sebesar 0.000 dan nilai pada koefisien regresi memiliki nilai yang positif. Diperolehnya hasil pengaruh positif dari Total financing terhadap perataan laba tersebut memberikan implikasi bahwa perusahaan yang memiliki jumlah pembiayaan yang tinggi, akan memiliki kecenderungan untuk melakukan praktik perataan laba yang tinggi. Hal ini dapat disebabkan oleh semakin tinggi bank syariah menyalurkan pembiayaan maka semakin tinggi kemungkinan bank sayriah untuk memperoleh keuntungan dari pembiayaan yang disalurkan oleh bank syariah tersebut. Karena adanya keuntungan yang didapat bank syariah dari jumlah pembiayaan yang disalurkan maka kecenderungan bank syariah untuk melakukan praktik perataan laba semakin tinggi.

Hasil uji statistik pada tabel 4 menunjukkan hasil GDP tidak berpengaruh terhadap perataan laba dengan nilai Prob. $>0.05$ yaitu sebesar 0.435 . GDP merupakan nilai barang atau jasa dalam 
suatu negara yang diproduksi oleh faktor- faktor produksi milik warga negara Indonesia. Keterkaitan GDP dengan dunia perbankan adalah terkait mengenai saving, sedangkan salah satu kegiatan bank sebagai mediasi sektor keuangan adalah mengumpulkan dana dari masyarakat dan menyalurkannya dalam bentuk investasi (Stiawan, 2009). Keuntungan dari investasi tersebut akan menjadi bagian dari profitabilitas bank syariah. Jadi, dapat disimpulkan bahwa GDP tidak berpengaruh terhadap perataan laba, karena GDP hanya terkait dengan investasi dalam bentuk tabungan yang dilakukan oleh masyarakat kepada bank syariah.

Hasil uji statistik pada tabel 7 menunjukkan hasil inflasi tidak berpengaruh terhadap Perataan Laba dengan nilai Prob. $>0.05$ yaitu sebesar 0,517. Penelitian ini sejalan dengan penelitian dari Rice dan Salim (2014) yang menyatakan bahwa tingkat inflasi tidak berpengaruh terhadap tindakan perataan laba. Hal ini dikarenakan dalam penyusunan laporan keuangan bank mengikuti kondisi perekonomian. Artinya, apabila terjadi inflasi maka nasabah beramai-ramai menarik uangnya dari bank karena meningkatnya harga kebutuhan pokok dan menyebabkan nasabah harus menarik uang tabungannya pada bank. Sebaliknya, ketika tingkat inflasi rendah, masyarakat akan menabung karena harga dari kebutuhan pokok menurun dan menyadarkan masyarakat untuk menyimpan sisa uangnya pada bank. Sehingga, bank memperoleh banyak sumber dana dan dapat menyalurkan lebih banyak dana kepada pihak yang membutuhkan dan bank syariah memperoleh bagi hasil atau margin dari pembayaran masyarakat tersebut. Jadi, inflasi tidak mempengaruhi perataan laba karena inflasi hanya berkaitan mengenai simpanan nasabah pada bank syariah dan memperoleh keuntungan dari pembayaran pembiayaan yang dibayarkan nasabah bukan berkaitan dengan praktik perataan laba.

\section{Penutup}

Variabel Earning Before Tax And Provisions (EBTP) berpengaruh positif signifikan terhadap perataan laba. Artinya apabila bank memiliki tingkat keuntungan yang tinggi maka kecenderungan bank untuk melakukan perataan laba akan semakin tinggi. Variabel Non Performing Financing (NPF) berpengaruh negatif signifikan terhadap perataan laba. Artinya apabila tingkat risiko pembiayaan meningkat maka kecenderungan bank untuk melakukan perataan laba akan semakin rendah. Variabel Good Corporate Governance yang diproksikan dengan keberadaan Dewan Pengawas Syariah tidak berpengaruh terhadap perataan laba. Hal ini karena masih ditemukan adanya kelemahan pengawasan terhadap bank umum syariah. Variabel Total Pembiayaan (Total Financing) berpengaruh positif signifikan terhadap perataan laba. Hal ini memberikan implikasi bahwa perusahaan yang memiliki jumlah pembiayaan yang tinggi, akan memiliki kecenderungan untuk melakukan praktik perataan laba yang besar. Variabel Gross Domestic Product (GDP) tidak berpengaruh terhadap perataan laba. karena GDP hanya terkait dengan investasi yang dilakukan oleh masyarakat kepada bank syariah. Variabel Inflasi tidak berpengaruh terhadap perataan laba. Karena dalam penyusun laporan keuangan bank juga mengikuti kondisi perekonomian.

Adanya kelemahan dari peran Dewan Pengawas Syariah mengenai pengawasan operasional bank umum syariah sebaiknya melakukan peningkatan dan evaluasi dari fungsi Dewan Pengawas Syariah itu sendiri. Hal ini karena peran Dewan Pengawas Syariah sangat penting dalam pengawasan kegiatan operasional bank umum syariah untuk mengukur tingkat kepatuhan bank umum syariah terhadap prinsip syariah. Untuk penelitian selanjutnya diharapkan menggunakan laporan keuangan triwulan dan menambah periode tahun agar memperoleh hasil yang maksimal dan menambah variabel faktor eksternal seperti siklus bisnis yang memungkinkan adanya pengaruh terhadap perataan laba. Serta diharapkan dapat menemukan lebih banyak lagi aktivitas tentang manipulasi dan menggunakannya dalam model penelitian berikutnya. 


\section{Daftar Pustaka}

Arisandy, Y. (2015). Manajemen Laba Dalam Perspektif Islam. Jurnal Mizani Vol. 25 No. 2.

Assih, P., \& Gudono. (2000). Hubungan Tindakan Perataan Laba dengan Reaksi Pasar atas Pengumuman Informasi Laba Perusahaan yang Terdaftar di Bursa Efek Jakarta. Jurnal Riset Akuntansi Indonesia, 17-34.

Boulila, N. (2010). Do Islamic banks use loan loss provisions to smooth their results? Journal of Islamic Accounting and Business Research.

Dunil, Z. (2005). Bank Auditing Risk-Based Audit Dalam Pemeriksaan Perkereditan Bank Umum. Jakarta: PT Indeks Kelompok Gramedia.

Iqbal, Z., \& Mirakhor, A. (2007). An Introduction to Islamic Finance Theory and Practice. Singapore: Wiley.

Irawati, Z., \& Maya, A. (2007). Analisis Perataan Laba (Income Smoothing): Faktor Yang Mempengaruhinya Dan Pengaruhnya Terhadap Return Dan Risiko Saham Pada Perusahaan Go Public Di Bursa Efek Jakarta.

Kustono, A. S. (2010). Indeks Eckel sebagai Pengidentifikasi Perataan Penghasilan yang Tidak Reliable. Jurnal Kenangan dan Perbankan.

Kustono, A. S. (2010). Indeks Eckel sebagai Pengidentifikasi Perataan Penghasilan Yang Tidak Reliable. Jurnal Kenangan dan Perbankan.

Laela, S. (2012). Kualitas Laba dan Corporate Governance : Benarkah Kualitas Laba Bank Syariah Lebih Rendah dari Bank Konvensional. Jurnal Akuntansi dan Kenangan Indonesia, 22-42.

Mahulete, U. K. (2016). Pengaruh DAU dan PAD terhadap Belanja Modal di Kabupaten/Kota Provinsi Maluku. Skeripsi.

Mawardi, W. (2005). Analisis Faktor ynag Mempengaruhi Kinerja Keuangan Bank Umum di Indonesia (Studi Kasus Pada Bank Umum dengan Total Aset Kurang dari 1 Triliun). Jumal Bisnis dan Strategi Vol.14 No.1.

Oktaviyanti. (2013). Pengaruh Volatilitas Laba pada Manajemen Laba Perbankan dengan Moderasi Self Assesment Corporate Governance, Struktur Kepemilikan dan Kualitas Audit. Tesis.

Pe'rez, D., Salas, V., \& Saurina, J. (2006). Earnings and Capital Management In Alternative Loan Loss Provisions Regulatory Regimes. Banco De Escape No. 0614.

Prabowo, B. A., \& Jamal. (2017). Peranan Dewan Pengawas Syariah terhadap Praktik Kepatuhan Syariah dalam Perbankan Syariah di Indonesia. Jurnal Hukkum Ius Quaia Faculty Vol. 24.

Prakarsa, R. A., \& Setiawan, S. (2018, October). Pengaruh Profitabilitas, Leverage, dan Ukuran Perusahaan Terhadap Praktik Perataan Laba (Studi Pada Perusahaan Keuangan Sub Sektor Perbankan Yang Terdaftar Di Bursa Efek Indonesia Periode 2015-2017). In Prosiding Industrial Research Workshop and National Seminar (Vol. 9, pp. 719-727).

Rezhita, N., \& Sohnhadji, N. (2017). Pengaruh Perkembangan Likuiditas, Inflasi, CAR, ROA, dan LDR Terhadap Cadangan Kerugian Penurunan Nilai (CKPN) Pada Industri Perbankan Yang Go Public di BEI. Artikel Ilmiah.

Rinanti, R. (2012). Analisis Faktor-Faktor Yang Mempengaruhi Penyisihan Penghapusan Aktiva Produktif. Jurna Bisnis Strategi.

Salim, S., \& Rice. (2014). Pengaruh Faktor Eksternal Dan Internal Perusahaan Terhadap Tindakan Perataan Laba. Jurnal Wira Ekonomi Mikroskil, Vol. 4, No. 02.

Stiawan, A. (2009). Analisis Pengaruh Faktor Makroekonomi, Pangsa Pasar dan Karakteristik Bank 
Terhadap Profitabilitas Bank Syariah. Skripsi.

Sulistiyanto, S. (2008). Manajemen Laba : Teori Dan Model Empiris. Jakarta: PT Grasindo, Anggota Ikapi.

Syahfandi, R. (2012). Faktor-Faktor Yang Mempengaruhi Perataan Laba Penyisihan Pengahapusan Aktiva Produktif. Skripsi.

Syahfandi, R. (2012). Faktor-Faktor Yang Mempengaruhi Perataan Laba Penyisihan Penghapusan Aktiva Produktif: Praktik Manajemen Laba pada Perbankan Syariah di Indonesia.

Tobing, R. W., \& Anggorowati, N. I. (2009). Perataan Laba Melalui Penyisihan Penghapusan Aktiva Produktif (PPAP) Sektor Perbankan. Jurnal Akuntabilitas.

Tobing, W., \& Anggrowati, N. I. (2009). Perataan Laba Melalui Penyisihan Penghapusan Aktiva Produktif Sektor Perbankan. Jurnal Akuntabilitas.

Utari, R., Gustini, E., \& Tripermata, L. (2017). Pengaruh Profitabilitas, Financial Leverage, Dan Dividend Payout Ratio Terhadap Perataan Laba Pada Perusahaan. Jurnal Ilmiah Ekonomi Global Masa Kini Volume 8 No.02.

Wijayanti, R., \& Diyanti, V. (2016). Pengaruh Volatilitas Laba, Perataan Laba dan Corporate Governance terhadap Kualitas Laba Bank Syariah dan Konvensional. Jumal Akuntansi dan Investasi, Vol. 18 No. 1, 66-79. 